J. Lake Sci. (湖泊科学), 2014, 26(3):358-364

http: //www. jlakes.org. E-mail : jlakes@niglas.ac.cn

(C) 2014 by Journal of Lake Sciences

\title{
太湖藻类水平漂移特征及其影响因素”
}

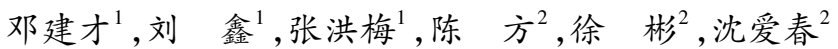 \\ (1: 中国科学院南京地理与湖泊研究所湖泊与环境国家重点实验室, 南京 210008) \\ (2: 太湖流域管理局水文水资源监测中心,无锡 214024)
}

\begin{abstract}
摘 要: 采用原位观测平台,研究分析了太湖竺山湾风速、湖流流速、波高以及藻类水平漂移特征及其影响因素,结果表 明日间藻类水平漂移速率呈锯齿式交替特征, 日内藻类水平漂移速率变化幅度大; 藻类水平漂移速率与风速之间呈显著 线性正相关; 当 $0.02 \mathrm{~m}<$ 有效波高 $<0.1 \mathrm{~m}$ 时, 藻类水平漂移速率与有效波高呈显著线性负相关, 当有效波高 $>0.1 \mathrm{~m}$ 时, 波浪会显著改变藻类运动方式, 破坏藻类表层聚集形态; 湖流对藻类水平漂移速率无显著性影响; 藻类水平漂移方向受 湖流流向和风向的共同作用; 藻类水平漂移速率与风速、波高、湖流流速间关系可用多元线性方程表达, 且拟合度良好, 可为藻类水华预测模型构建提供依据.
\end{abstract}

关键词: 太湖;原位观测;漂移速率;影响因素;竺山湾

\section{Characteristics and impact factors of algal horizontal drifting in Lake Taihu}

\author{
DENG Jiancai ${ }^{1}$, LIU Xin ${ }^{1}$, ZHANG Hongmei ${ }^{1}$, CHEN Fang ${ }^{2}$, XU Bin ${ }^{2} \&$ SHEN Aichun ${ }^{2}$ \\ (1: State Key Laboratory of Lake Science and Environment, Nanjing Institute of Geography and Limnology, Chinese Academy \\ of Sciences, Nanjing 210008, P. R. China) \\ (2: Taihu Hydrology and Resources Survey Bureau, Wuxi 214024, P. R. China)
}

Abstract: In-situ observation platform was used to investigate impacts of wind speed, lake current and significant wave height (SWH) on algal horizontal drifting velocity in Zhushan Bay, Lake Taihu. Results showed that algal drifting rate on different observation days was alternating zigzag-type characteristics, and then the amplitude of algae drifting velocity within one day became obviously different. A significant positive linear correlation between algal drifting velocity and wind speed was observed. When SWHs are within the range of $0.02 \mathrm{~m}$ and $0.1 \mathrm{~m}$, there was a dramatically negative linear correlation between algal drifting rate and SWHs; when SWHs were larger than $0.1 \mathrm{~m}$, wave could markedly change algae drifting patterns and destroy algae tablet layers. Lake current had insignificant effect on the algal drifting rates, although the direction of algal transport was regulated by the directions of lake current and wind. The relationships between algae horizontal drifting rates and wind speeds, SWHs and lake flow may be expressed by a multiple linear equation with the goodness of fit, which provided a theoretical basis for the construction of algal bloom prediction model.

Keywords: Lake Taihu; in-situ observation; drifting velocity; impact factors; Zhushan Bay

大多数水华藻类具有伪空胞 ${ }^{[1]}$, 通过浮力调节作用, 实现在水体垂向的移动 ${ }^{[2]}$. 在静风或弱风条件下, 藻类伪空胞的浮力调控使其进人水体表层获得充足的光照和 $\mathrm{CO}_{2}$ 源 ${ }^{[3]}$, 也可使其吸收深水处的营养物质, 弥补垂向上光与营养不能同时满足的缺陷 ${ }^{[4]}$. 藻类漂移与水流运动有关, 风导致湖泊表层水体的水平运动, 可驱使藻类向下风向区聚集; 风还能引起湖泊水体的水平循环, 使藻类聚集在水平循环的中心区域 ${ }^{[5-6]}$. 近 年来, 国内外学者开展了风对藻类分布影响的研究, 发现低风速有利于藻类聚集与水平运动, 而高风速则会 破坏藻类在水体表层聚集 ${ }^{[7-8]}$. 朱永春等 ${ }^{[9]}$ 运用数学模型模拟了水体藻类迁移过程, 结果表明不同风场对湖 泊水体中藻类的水平分布有显著的影响, 当风速小于临界风速 $(2 \sim 3 \mathrm{~m} / \mathrm{s})$ 时, 水体表面分布的藻类顺着风

* 国家自然科学基金项目 (41271213) 和水利部公益性行业科研专项经费项目 (201001029) 联合资助. 2013-04-16 收稿;2013-07-11 收修改稿. 邓建才(1978 ), 男,博士, 副研究员;E-mail :jcdeng@ niglas. ac. cn. 
向迅速向迎风岸漂移,形成藻类大量堆积. 范成新等 ${ }^{[10]}$ 研究发现, 当季节盛行风速小于 $4 \mathrm{~m} / \mathrm{s}$ 时, 水体表层 藻类水华层发生大面积迁移; 当季节盛行风速大于 $4 \mathrm{~m} / \mathrm{s}$ 时, 水体表层水华由趋表分布转变为垂向均一分 布. 这些研究定性描述了风在藻类空间分布上的作用以及藻类易在某区域聚集的主要原因. 白晓华等 ${ }^{[11]}$ 建 立了风速与水华漂移速率的关系表达式,并利用该方程计算出梅梁湾外来席状水华藻类的面积,这为剖析 风与藻类空间分布的定量关系提供了思路. 目前, 有关藻类水平漂移速率及其影响因素的研究较少, 除风速 外, 其他因素的影响鲜有涉及. 因此, 本文采用原位观测平台, 结合统计分析手段, 研究风速、波浪、湖流对藻 类水平漂移速率的影响, 旨在探讨多种因素共同作用下藻类水平漂移特征, 为藻类水华预警研究提供科学 依据.

\section{1 材料与方法}

\section{1 研究区域选择与观测平台建设}

竺山湾是太湖西北部一半封闭湖湾, 湾内水流以逆时针环流为主, 湾外水流环流流向不定, 且流速小, 不利于物质运输交换 ${ }^{[12]}$. 竺山湾是太湖水污染最为严重的区域,水质常年处于劣 $\mathrm{V}$ 类 ${ }^{[13]}$. 藻类水华呈常态 化, 暴发频率高、强度大、覆盖面积广, 且每年 4-11 月水体表面有藻覆盖, 在适当的风速条件下, 藻类运动 以水平迁移为主,并在下风向区堆积,这使竺山湾成为开展藻类水平漂移特征研究的理想区域之一.

藻类水平漂移观测平台 $\left(31^{\circ} 24^{\prime} \mathrm{N}, 120^{\circ} 3^{\prime} \mathrm{E}\right)$ 位于竺山湾湾口, 其边长为 $16 \mathrm{~m}$, 距离东、西两岸分别为 1 、 $2 \mathrm{~km}$. 藻类水平漂移观测平台由 “十” 字型栈道将四周的栈桥相连, 栈桥桥面宽度为 $0.8 \mathrm{~m}$ 、距离水面 $1 \mathrm{~m}$ (图 $1)$. 藻类水平漂移观测平台上安装了小型气象仪、流速仪、波浪仪,分别用来记录风速与风向、湖流和波浪 参数.

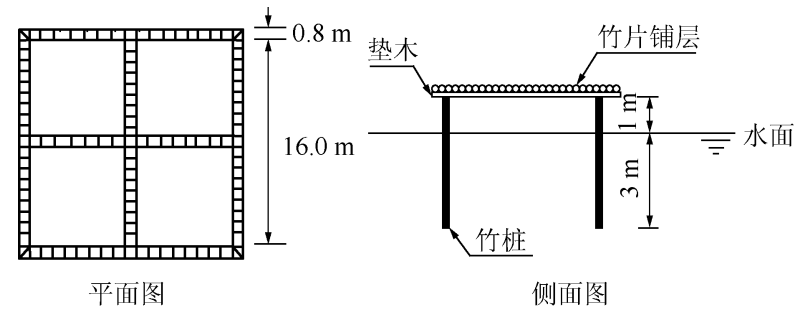

图 1 藻类漂移观测平台结构示意图

Fig. 1 Schematic diagram of algae drift observation platform

\section{2 观测指标}

基于藻类漂移观测平台,于 2011 年 8 月 16- 26 日和 2012 年 8 月 20-26 日开展藻类漂移聚集特征研 究, 以表层聚集形态的藻类为观测对象, 用秒表记录藻类从观测起点漂移至终点经历的时间, 由运动距离和 时间计算出藻类水平漂移的平均速率; 用罗盘仪确定藻类水平漂移方向; 用水样分层采样器同步采集水下 $50 、 150$ 和 $250 \mathrm{~cm}$ 处水样,并分析其叶绿素 a 含量; 从流速仪、波浪仪和气象仪中读取对应时刻的湖流、波浪 参数和风速、风向等数据. 采用 SPSS 16.0 处理与分析实验数据.

\section{2 结果与分析}

\section{1 藻类水平漂移速率变化特征}

在藻类漂移原位观测实验期间, 藻类水平漂移速率最大值为 $0.327 \mathrm{~m} / \mathrm{s}$, 出现在 2012 年 8 月 23 日; 最小 值则为 $0.01 \mathrm{~m} / \mathrm{s}$, 出现在 2012 年 8 月 20 日; 藻类水平漂移速率的平均值为 $0.086 \pm 0.045 \mathrm{~m} / \mathrm{s}, 2011$ 年 8 月 16-26 日藻类水平漂移速率的平均值为 $0.079 \pm 0.022 \mathrm{~m} / \mathrm{s}, 2012$ 年 8 月 $20-26$ 日藻类水平漂移速率的平 均值为 $0.094 \pm 0.061 \mathrm{~m} / \mathrm{s}$. 藻类水平漂移速率日际变化呈锯齿式交替特征, 即增加一减小一增加的往复循环, 且 2011 年 8 月日均藻类水平漂移速率的变化幅度明显弱于 2012 年 8 月,这是因为除藻类生物量存在差异 外, 藻类水平漂移实验期间受到外部环境条件 ( 风速、湖流和波浪等) 的影响, 与 2012 年同期相比,2011 年 8 


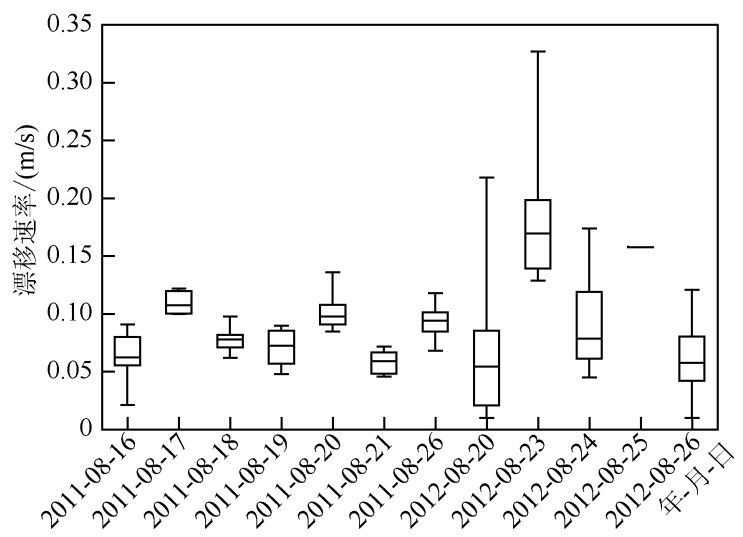

图 2 藻类水平漂移速率日际、日内变化特征

Fig. 2 Diurnal and inter-diurnal variation characteristics of algal horizontal drift rate

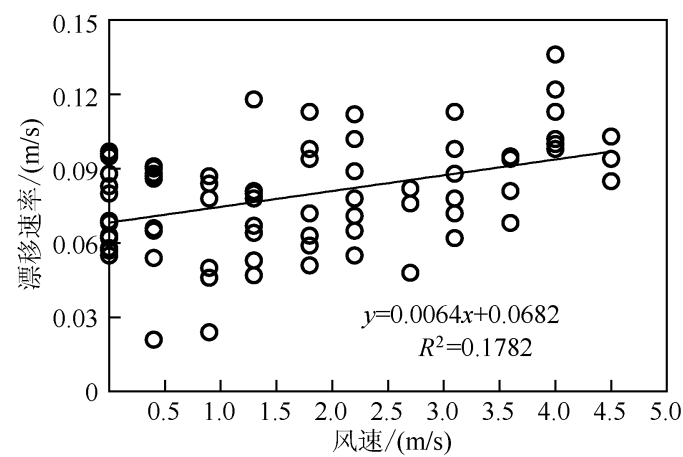

图 3 风速与藻类水平漂移速率的关系

Fig. 3 Relationship between wind velocity and algal horizontal drift rate
月藻类水平漂移实验期间外部环境条件的变化 相对较小 (图 2). 藻类水平漂移速率日内变化幅 度也存在较大差异, 极差和相对极差变化范围 分别为 $0 \sim 0.208 \mathrm{~m} / \mathrm{s}$ 和 $0 \sim 2.88$, 且极差和相对 极差最大值均出现在 2012 年 8 月 20 日,表明当 日外部环境条件变化相当激烈; 极差和相对极 差最小值分别为 $0.022 \mathrm{~m} / \mathrm{s}$ 和 0.2 , 均出现在 2011 年 8 月 17 日,尽管 2012 年 8 月 25 日极差 和相对极差均为 0 , 但因风较大, 仅获取了 1 个 藻类水平漂移数据 (图 2). 与 2011 年相比, 2012 年藻类漂移实验期间, 藻类水平漂移速率日内 变化幅度明显较大, 表明影响藻类水平漂移速 率的环境条件日内变化也比较剧烈.

\section{2 藻类水平漂移的影响因素}

2.2.1 风速对藻类水平漂移速率的影响 藻类 水平漂移速率与风速的关系表明 (图 3), 当风速 小于 $4.5 \mathrm{~m} / \mathrm{s}$ 时, 藻类水平漂移速率随着风速增 加呈增大趋势, 二者之间的关系可用线性方程 $\left(y=0.0064 x+0.0682, R^{2}=0.1782, P<0.01\right)$ 表 示, 运用 SPSS 统计分析表明, 风速与藻类水平漂 移速率之间达到极显著线性正相关. 值得注意的 是, 当风速为 0 时, 藻类仍以一定的速率运动, 表 明蓝藻漂移速率还受除风以外其他因素的影响.

2.2 .2 波高对藻类水平漂移速率的影响 波浪是 风能转化为波能过程的外在表现形式, 因此,波浪 也会对藻类水平漂移产生一定的影响. 当有效波 高 $<0.02 \mathrm{~m}$ 时, 水面仅出现波幅小的微波, 藻类 水平漂移速率受表层湖流影响较大, 而风浪对其 产生的影响相对较弱 (图 4). 因此波高对藻类水

平漂移速率影响很小, 也无明显的规律.

当 $0.02 \mathrm{~m}<$ 有效波高 $<0.1 \mathrm{~m}$ 时, 藻类水平漂移速率随着有效波高的增加而降低, 相关式可表达为: $y=$ $0.1264-1.08 x\left(R^{2}=0.5793\right)$, 达到了显著相关水平 $(P<0.05)$ (图 4). 这是因为: 一方面有效波高增加使波 浪扰动的幅度加大, 水体表面藻类的运动方式由直线型转变为耦合了风浪作用的波浪型, 藻类波浪式运动, 增加其绝对运动路径, 由此增加了其运动时间, 导致藻类水平漂移速率相对下降; 另一方面尽管竺山湾也存 在主导风向, 但风浪作用方向也会瞬时变化, 致使水体表层聚集的藻类往返式运动, 甚至是运动方向也发生 变化,这会使藻类在一定路程内的绝对时间增加,从而导致其漂移速率下降.

当有效波高 $>0.1 \mathrm{~m}$ 时, 波浪运动振幅显著增加, 其蒀含的能量也逐渐增大, 最终导致表层聚集的藻类 形态破坏, 蓝藻也由在表层聚集态快速转换为水体上下混合均匀态, 藻类运动方式发生显著变化, 藻类水平 漂移观测受阻.

2.2 .3 湖流对藻类水平漂移速率的影响 湖流流速与藻类水平漂移速率未呈现出明显的规律性 (图 5), 这 是由于湖流数据是各水层湖流的平均值, 而不是表层水体湖流特征值造成的, 尽管 ADP 流速仪可以测定获 得表层水体湖流, 但因无法剔除包含了风速以及其他机械扰动因素的信息, 而不能直接使用; 另外各水层流 速存在方向差异, 对表层藻类水平漂移速率的影响也呈现出矢量变化特征. 当湖流流速小于 $0.01 \mathrm{~m} / \mathrm{s}$ 时, 藻 类水平漂移速率仍然存在, 这可能是由于受到风速或波浪的影响; 当湖流流速大于 $0.01 \mathrm{~m} / \mathrm{s}$ 时, 藻类水平漂 
移速率并未显著增加,这体现了藻类水平漂移是多种因素综合作用的结果 (图 5 ). 值得一提的是, 2011 年 8 月 16 日 13 点 31 分时 (图 5 方框中的点), 湖流流速为 $0.022 \mathrm{~m} / \mathrm{s}$, 而藻类漂移的速率则为当日漂移速率的 最低值, 这是因为此时风向与湖流方向存在一定夹角, 使得藻类漂移方向、风向、湖流流向三者不重合,这进 一步表明藻类水平漂移受到多种因素的影响.

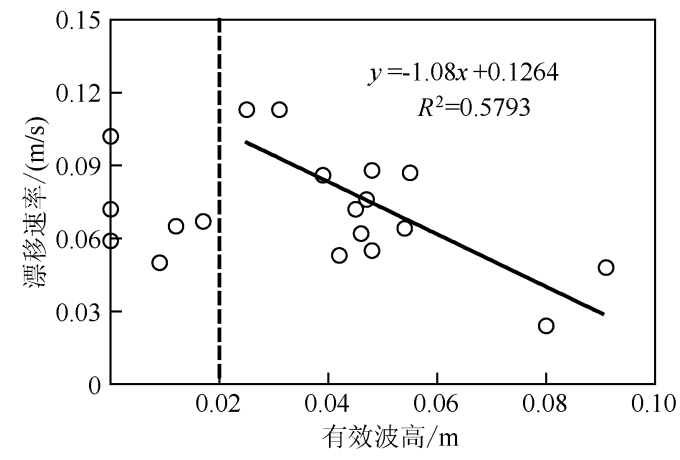

图 4 蓝藻漂移速率与有效波高的关系

Fig. 4 Relationship between efficient wave height and algal horizontal drift rate

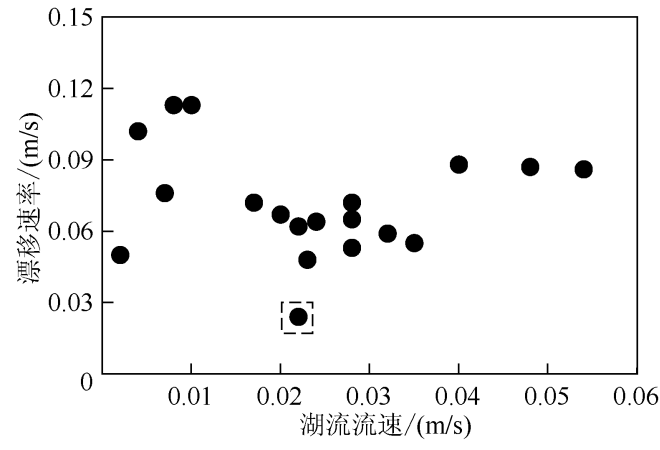

图 5 湖流对藻类漂移速率的影响

Fig. 5 Impact of lake current on algal horizontal drift rate

2.2.4 风速风向、湖流流向与藻类漂移速率的矢量关系 水体藻类水平漂移方向受到湖流流向、风向的共同 影响. 从 2011 年 8 月 20 日藻类水平漂移方向与风速、湖流大小及其风向流向的矢量变化关系可以看出, 湖 流流向和风向均对藻类水平漂移方向产生影响 (表 1). 在 9:00 左右, 尽管风速 $(3.6 \sim 4.5 \mathrm{~m} / \mathrm{s}$ ) 和湖流流速 $(0.023 \sim 0.042 \mathrm{~m} / \mathrm{s})$ 相对较大, 风向为 $\mathrm{E}$, 湖流流向为 SSE, 但因风向与湖流对水体表层藻类作用方向不一 致, 使得藻类水平漂移方向介于 $\mathrm{E}$ 和 SSE 方向中间的 SE 方向, 且水平漂移速率并未呈明显的增加趋势; 在 $13: 00$ 左右, 风向由 $\mathrm{E}$ 变为 $\mathrm{SSE}$, 而湖流流向仍为 $\mathrm{SSE}$, 观测到的藻类向 SSE 方向水平漂移, 藻类水平漂移方 向与风速方向、湖流流向一致, 虽然风速 $(2.2 \sim 4.0 \mathrm{~m} / \mathrm{s})$ 和湖流流速 $(0.007 \sim 0.015 \mathrm{~m} / \mathrm{s})$ 相对较小, 但藻类 水平漂移速率显著增大.

表 1 藻类水平漂移方向与风向、湖流流向的关系

Tab. 1 Relationships between algal horizontal drift direction and wind, current direction

\begin{tabular}{llclllll}
\hline $\begin{array}{r}\text { 观测 } \\
\text { 时间 }\end{array}$ & $\begin{array}{c}\text { 漂移速率/ } \\
(\mathrm{m} / \mathrm{s})\end{array}$ & $\begin{array}{c}\text { 藻类漂 } \\
\text { 移方向 }\end{array}$ & $\begin{array}{c}\text { 风速/ } \\
(\mathrm{m} / \mathrm{s})\end{array}$ & 风向 & $\begin{array}{c}\text { 湖流流速/ } \\
(\mathrm{m} / \mathrm{s})\end{array}$ & $\begin{array}{l}\text { 湖流 } \\
\text { 流向 }\end{array}$ & 备注 \\
\hline $9: 00$ & 0.10 & $\mathrm{SE}$ & 4.5 & $\mathrm{E}$ & 0.042 & $\mathrm{SSE}$ & 藻类水平漂移方向与风向、湖流流向不一致 \\
$9: 05$ & 0.09 & $\mathrm{SE}$ & 4.5 & $\mathrm{E}$ & 0.023 & $\mathrm{SSE}$ & \\
$9: 07$ & 0.09 & $\mathrm{SE}$ & 3.6 & $\mathrm{E}$ & 0.033 & $\mathrm{SSE}$ & \\
$9: 09$ & 0.09 & $\mathrm{SE}$ & 4.5 & $\mathrm{E}$ & 0.031 & $\mathrm{SSE}$ & \\
$13: 04$ & 0.10 & $\mathrm{~S}$ & 2.2 & $\mathrm{~S}$ & 0.007 & $\mathrm{SSE}$ & 藻类水平漂移方向与风向一致,与流向不一致 \\
$13: 06$ & 0.09 & $\mathrm{~S}$ & 3.1 & $\mathrm{~S}$ & 0.010 & $\mathrm{SSE}$ & \\
$13: 10$ & 0.11 & $\mathrm{SSE}$ & 3.1 & $\mathrm{SSE}$ & 0.015 & $\mathrm{SSE}$ & 藻类水平漂移方向与风向、湖流流向一致 \\
$13: 13$ & 0.14 & $\mathrm{SSE}$ & 4.0 & $\mathrm{SSE}$ & 0.009 & $\mathrm{SSE}$ & \\
\hline
\end{tabular}

\section{3 风速、波浪与湖流流速对藻类漂移速率的共同作用}

根据风速 $\left(V_{\text {风速 }}\right)$ 、波高 $\left(H_{\text {波高 }}\right)$ 和湖流流速 $\left(V_{\text {湖流 }}\right)$ 优化组合预测藻类水平漂移速率, 其多元线性回归方

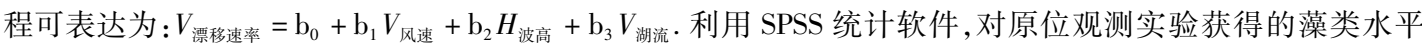
漂移速率、风速、波高、湖流流速成组对应数据进行多元线性回归分析, 获得藻类水平漂移速率与风速、波 高、湖流流速等变量的偏回归系数 (表 2), 多元线性回归表达式为 $V_{\text {漂移速率 }}=0.049+0.018 V_{\text {风速 }}-0.470 H_{\text {波高 }}+$

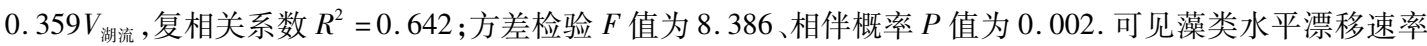


表 2 藻类漂移速率与风速、波浪、湖流影响 因素的多元线性回归参数

Tab. 2 Statistical parameters from multiple linear regression among algae drift rate and wind, wave and flow

\begin{tabular}{crrrr}
\hline 参数 & \multicolumn{2}{c}{ 非标化系数 } & & \\
\cline { 2 - 3 } & 偏回归系数 & 标准误 & & \\
\hline 常数 & 0.049 & 0.018 & 2.680 & 0.018 \\
风速 & 0.018 & 0.005 & 3.821 & 0.002 \\
湖流流速 & 0.359 & 0.524 & 0.684 & 0.505 \\
波高 & -0.470 & 0.218 & -2.159 & 0.049 \\
\hline
\end{tabular}
作用 ${ }^{[5,8,15]}$.

风速调节藻类吸收营养盐及其浮力大小, 从而影响到藻类生长与聚集形态. 风速风向与藻类水华面积 关系密切, 通常条件下, 湖面风速较小, 使得藻颗粒上浮聚集, 藻类水华面积迅速扩大; 反之, 藻类水华面积 迅速减小 ${ }^{[14]}$. 在适当的风速风向作用下, 藻类大量聚集形成席状藻类水华, 对湖泊生态系统的功能造成不利 影响. 白晓华等 ${ }^{[11]}$ 采用室内风箱水槽实验方法, 建立了风速与水华漂移速度的指数相关方程, 并计算出漂移 进入梅梁湾的水华可占整个水华面积的 3.7\% 13. 3\% . 本研究借助原位观测手段, 发现在一定风速范围 内, 藻类水平漂移速率与风速呈显著线性正相关, 但当风速达到 $4 \mathrm{~m} / \mathrm{s}$ 时, 水体表层的藻类状态逐渐由近似 席状向分散颗粒态过渡, 澡类席状层受到破坏的几率也在逐渐增加.

本文通过分析水面以下 $0.5 、 1.5$ 和 $2.5 \mathrm{~m}$ 处叶绿素 $\mathrm{a}$ 浓度发现, 不同水层中叶绿素 a 浓度随风速增减 出现了明显变化 (图 6). 当风速小于 $3.1 \mathrm{~m} / \mathrm{s}$ 时, 上层水体中叶绿素 $\mathrm{a}$ 浓度始终最高; 当风速增加时, 表层水 体中叶绿素 a 浓度开始下降, 中、下层水体中叶绿素 a 浓度很快增加, 导致藻类在水柱中趋于均匀分布. 可 见, 水动力条件对藻类垂向空间分布格局具有显著的影响. 由于原位实验无法确保水体初始的藻类密度维 持不变,使得不同风速条件下各层水体中叶绿素 $\mathrm{a}$ 浓度差异较大.

$\mathrm{Wu}$ 等 ${ }^{[6]}$ 研究表明湖流对水华区域澡类数量的贡献率仅为 $1 \% \sim 2 \%$, 而大量藻类来源于风驱动下的水 平漂移, 这与本研究获得的湖流与藻类水平漂移速率之间无显著相关性的结论是一致的. 这是因为竺山湾 湖流大小、流向均存在明显的分层以及各层之间存在着强烈的切变和混合作用 ${ }^{[16]}$. 然而杨清心 ${ }^{[17]}$ 认为表层 风生流携带藻类向对岸移动, 藻类随风生流在水中呈颗粒或者大片席状蓝藻聚集体在水面迁移运动. 风场 变化对表层湖流影响明显, 表层水体流向与风向基本一致. 这可能是湖流携带藻类水平运动的主要原因. 若 要辨析湖流在藻类水平漂移过程中的作用,则要进一步加强水体近表层湖流监测与信息提取.

波动缘于水面空气流动的湍流特性, 使得水面受到不均匀的正压力, 产生水面波动, 在波动产生以后, 波面的法向和切向同时受到正压力和雷诺应力的作用,加上波一波相互作用, 使得波浪得以成长 ${ }^{[18]}$. 波浪发 展不仅取决于风速大小, 还与风持续时间、风区长度有关 ${ }^{[19]}$, 波浪施加给沉积物表层的切应力是引起悬浮 物、营养盐浓度空间差异的重要因子 ${ }^{[20-21]}$. 波浪可导致藻类空间位置改变,一定强度的波浪使漂浮性藻类垂 向分布趋于均一, 从而破坏原已形成的聚集分布; 波浪易引起表层沉积物的再悬浮, 降低了湖水透明度与水 下光强, 从而限制藻类的生长 ${ }^{[17]}$. 然而, 波浪对藻类水平漂移速率的影响未见报道. 本文系统阐明了藻类水 平漂移速率与风速 $\left(V_{\text {风速 }}\right)$ 、波高 $\left(H_{\text {波高 }}\right)$ 和湖流流速 $\left(V_{\text {湖流 }}\right)$ 的多元线性关系, 除湖流外, 其他参数均达到显著 相关水平,可见不同气象和水文条件对藻类水平迁移以及水华暴发起至关重要的作用.

\section{4 结论}

1) 多元线性方程可表达藻类水平漂移速率与多种环境因素的关系, 其中风速和风向是藻类水平漂移速 率大小和方向的主控因子.

2) 风浪导致了藻类空间位置改变, 高强度风浪会使漂浮性藻类垂向分布趋于均一, 破坏席状藻类水华 

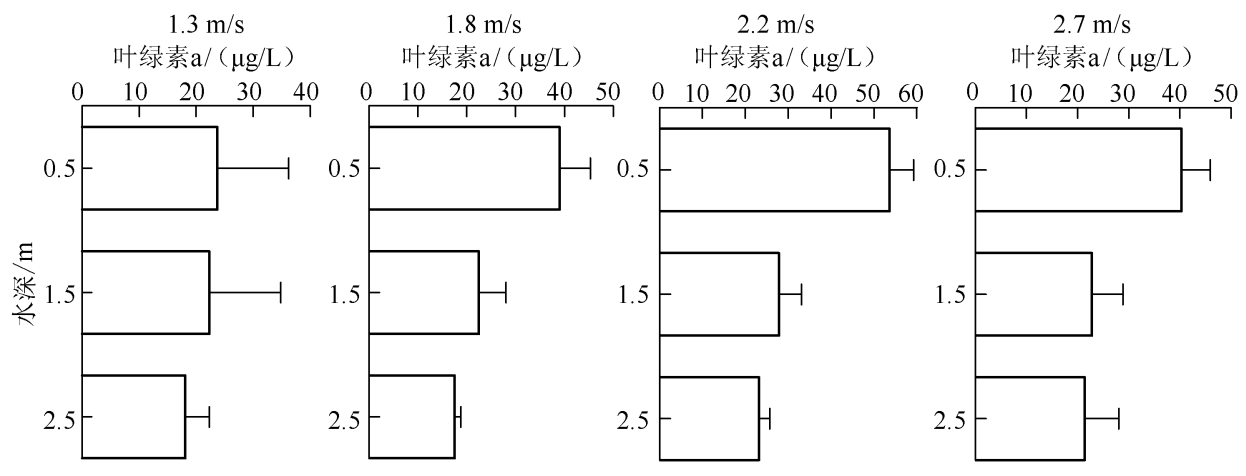

$3.1 \mathrm{~m} / \mathrm{s}$

$5.4 \mathrm{~m} / \mathrm{s}$

$5.8 \mathrm{~m} / \mathrm{s}$

叶绿素a/( $\mu \mathrm{g} / \mathrm{L})$ 叶绿素a/ $(\mu \mathrm{g} / \mathrm{L})$ 叶绿素a/ ( $\mu \mathrm{g} / \mathrm{L})$ $\begin{array}{lllllllll}0 & 10 & 20 & 30 & 40 & 50 & 60\end{array}$
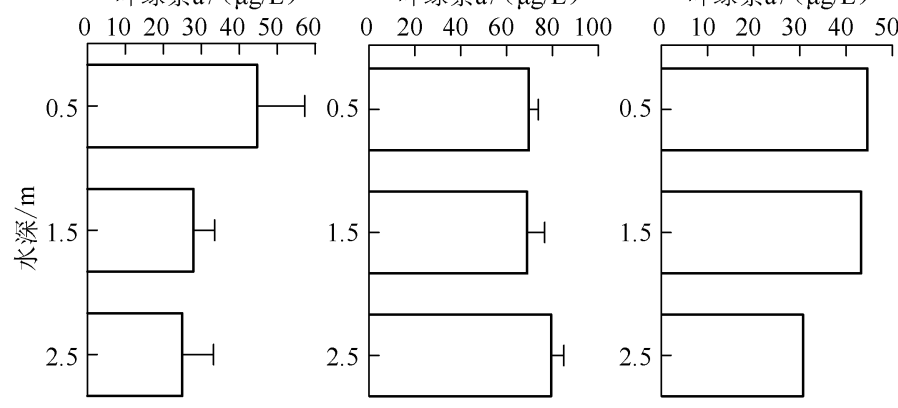

$>6.0 \mathrm{~m} / \mathrm{s}$ 叶绿素a/ $(\mu \mathrm{g} / \mathrm{L})$

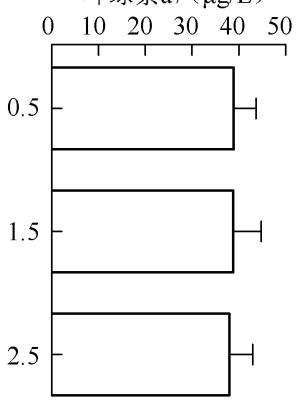

图 6 不同风速条件下各水层藻类垂向分布特征

Fig. 6 Vertical distribution characteristics of algae under different wind speed conditions

层,有利于降低湖泊水体藻类水华及其危害.

3 ) 湖流对藻类水平漂移速率的影响需要进一步研究.

\section{5 参考文献}

[ 1 ] Belenky M, Meyers R, Herzfeld J. Subunit structure of gas vesicles: a MALDI-TOF mass spectrometry study. Biophysical Journal, 2004, 86: 499-505.

[ 2 ] Medrano EA, Uittenbogaard RE, Pires L et al. Coupling hydrodynamics and buoyancy regulation in Microcystis aeruginosa for its vertical distribution in lakes. Ecological Modelling, 2013, 248 : 41-56.

[ 3 ] Walsby AE, Hayes PK, Roje R et al. The selective advantage of buoyancy provided by gas vesicles for planktonic cyanobacteria in the Baltic Sea. New Phytologist, 1997, 136: 407-417.

[ 4 ] Ganf GG, Oliver RL. Vertical separation of light and available nutrients as a factor causing replacement of green algae by blue-green algae in the plankton of a stratified lake. Journal of Ecology, 1982, 70 : 829-844.

[ 5 ] Podsetchine V, Schernewski G. The influence of spatial wind inhomogeneity on flow patterns in a small lake. Water Research, 1999, 33 : 3348-3356.

[ 6 ] Wu XD, Kong FX, Chen YW et al. Horizontal distribution and transport processes of bloom-forming Microcystis in a large shallow lake (Taihu, China). Limnologica, 2010, 40: 8-15.

[ 7 ] Small LF. Effect of wind on the distribution of chlorophyll a in clear lake, IOWA. Limnology and Oceanography, 1963, 8: $426-432$.

[ 8 ] Marce R, Feijoo C, Navarro E et al. Interaction between wind-induced seiches and convective cooling governs algal distribution in a canyon-shaped reservoir. Freshwater Biology, 2007, 52 : 1336-1352.

[ 9 ] 朱永春,蔡启铭. 风场对藻类在太湖中迁移影响的动力学研究. 湖泊科学, 1997,9:152-158.

[10］范成新, 陈宇炜. 夏季盛行风对太湖北部藻类水华分布的影响. 上海环境科学, 1998,17(8):4-6. 
[11] 白晓华, 胡维平, 胡志新. 2004 年夏季太湖梅梁湾席状漂浮水华风力漂移人湾量计算. 环境科学, 2005,26 (6) : $57-60$.

[12] 胡开明,逢 勇,谢 飞. 直湖港、武进港关闸对太湖竺山湖水环境影响. 湖泊科学, 2010,22:923-929.

[13] 吴俊锋,谢 飞,陈丽娜. 太湖重污染湖区底泥沉积物特性. 水资源保护,2011,27(4):74-78.

[14] 王文兰,任 健. 近地面风场变化对太湖蓝藻暴发影响的数值研究. 气象科学,2011,31:718-725.

[15] Rigosi A, Rueda FJ. Hydraulic control of short-term successional changes in the phytoplankton assemblage in stratified reservoirs. Ecological Engineering, 2012, 44 : 216-226.

[16] 吴挺峰. 前期风场控制的太湖北部湖湾水动力及对蓝藻水华影响. 湖泊科学, 2012,24:409-415.

[17] 杨清心. 太湖水华成因及控制途径初探. 湖泊科学,1996,8:67-74.

[18］罗潋葱,秦伯强,胡维平.太湖波动特征分析. 水动力学研究与进展,2004,19:664-670.

[19] 李一平,逢 勇,刘兴平.太湖波浪数值模拟. 湖泊科学, 2008,20:117-122.

[20] 汤露露,王 鹏,姚 琪. 太湖湖流、波浪、沉积物的三维数值模拟. 水资源保护,2011,27(2):1-5.

[21］李一平, 逢 勇, 罗潋葱. 波流作用下太湖水体悬浮物输运实验及模拟. 水科学进展, 2009,20:701-706. 